\title{
Ingrid SÁNCHEZ TéLLEZ
}

Universidad Iberoamericana, México.

ingrid.sanchez.tellez@gmail.com

ORCID iD: https://orcid.org/0000-0001-7299-9878

Recibido: 27/10/2020 - Aceptado: 15/03/2021

Para citar este artículo / To reference this article / Para citar este artigo

Sánchez Téllez, Ingrid. "El novelista como intelectual. La función pública de la novela de folletín en la Francia del siglo

XIX". Humanidades: revista de la Universidad de Montevideo, n 9, (202 I): 179-207.

https://doi.org//0.25185/9.8

\section{El novelista como intelectual. La función pública de la novela de folletín en la Francia del siglo XIX ${ }^{1}$}

\begin{abstract}
Resumen: El objetivo de este artículo es elucidar algunas de las condiciones históricas e intelectuales que propiciaron que la novela de folletín colaborara en la aparición del intelectual público. Para tal fin, el artículo rastrea, en algunos textos literarios del siglo xIX francés y algunas obras historiográficas, la correlación entre historia y literatura. Al recuperar las investigaciones que han dado cuenta de la aparición de la novela de folletín y el tipo de lector que produjo, es posible evidenciar la relación entre la prensa y la novela de folletín para el devenir del intelectual. Por consiguiente, este artículo indaga en las condiciones de producción de las nuevas formas literarias surgidas con la masificación del periódico: la novela de folletín. El artículo está dividido en tres partes. La primera parte es un estudio sobre el surgimiento de la novela de folletín y la novela de misterios como resultado del nuevo proceso de producción y popularización de la prensa. La segunda parte propone la figura del novelista como el primer intelectual público. La tercera parte redefine el término intelectual para establecer las implicaciones de la ética social del novelista intelectual en condición de prensa para la historia literaria actual. Esta reflexión se sitúa en el marco del conflicto social surgido tras el caso Dreyfus, momento histórico en el que surge el intelectual público.
\end{abstract}

Palabras clave: público, prensa política, novela de folletín, novela de misterios, narrativa del siglo xIX, intelectual. 


\title{
The novelist as an intellectual. The public function of the serialized novel in nineteenth- century France
}

\begin{abstract}
The purpose of this article is to elucidate some of the historical and intellectual conditions that led to the serialized novel collaborating in the emergence of the public intellectual. To this end, the article traces, from nineteenth century French literary texts and historiographical works, the correlation between history and literature. By recovering the investigations that have accounted for the appearance of the serialized novel and the type of reader it produced, it is possible to demonstrate the relationship between the press and the serialized novel for the future of the intellectual. Consequently, this article investigates the production conditions of the new literary forms that emerged with the massification of the newspaper: the serialized novel. The article is divided into three parts. The first part is a study on the emergence of the serialized novel and the mystery novel as a result of the new process of production and popularization of the press. The second part proposes the figure of the novelist as the first public intellectual. The third part redefines the term intellectual to establish the implications of the social ethic of the intellectual novelist as a press for current literary history. This reflection is situated within the framework of the social conflict that arose after the Dreyfus case, a historical moment in which the public intellectual emerged.
\end{abstract}

Keywords: public, political press, serial novel, mystery novel, 19th century narrative, intellectual.

\section{O jornalista como intelectual. A função pública da novela de folhetim na França do século XIX}

\begin{abstract}
Resumo: 0 objetivo do artigo é contextualizar o desenvolvimento e à evolução do jornal literário na primeira metade do século XIX e a sua repercussão no desenvolvimento da figura do intelectual público na segunda metade do mesmo século. 0 estudo foca principalmente em determinar a produção das novas formas literárias surgiram com a massificação do jornal, como a novela de folhetim ou da novela de mistérios, que por sua vez, produziram públicos leitores que foram a condição de possibilidade do autor como intelectual público. 0 artigo está dividido em três partes. A primeira parte é um estudo sobre o surgimento do romance serial e do romance de mistério a partir do novo processo de produção e popularização da imprensa. A segunda parte propõe a figura do romancista como o primeiro intelectual público. A terceira parte redefine 0 termo intelectual para estabelecer as implicações da ética social do romancista intelectual como uma imprensa para a história literária atual. Essa reflexão se situa no quadro do conflito social que surgiu após o caso Dreyfus, um momento histórico em que surgiu o intelectual público.
\end{abstract}

Palavras-chave: público, imprensa política, romance em série, romance de mistério, narrativa do século 19, intelectual. 
La novela de folletín surgió en el siglo xIx en la prensa francesa; su aparición favoreció la creación de nuevos públicos lectores. Este tipo de soporte literario generó las condiciones intelectuales para que la literatura adquiriese una función pública al denunciar los problemas más intensos de su época. La dimensión pública de la literatura coadyuvó en los procesos de democratización de los lectores para que la novela no perteneciese únicamente a las élites letradas ni al lugar de los especialistas. La publicación masiva de la prensa — publicaciones que alcanzaron un promedio de millón de ejemplares - produjo, entonces, nuevos lectores que se beneficiaron con el abaratamiento de costos y la apertura del mercado que, cada vez más ambicioso, seducía a diversos intereses políticos y literarios. De igual forma, la novela de folletín generó las posibilidades para el surgimiento de un tipo de intelectual público que mediara entre el pueblo y los problemas sociales de su época. Por consiguiente, la literatura decimonónica y la historia política de Francia mantuvieron una relación tensa y compleja durante el periodo de su conformación nacional. El caso Dreyfus (1894-1906) y la polémica del intelectual decimonónico muestran esta relación en pugna y constituyen un momento particular de la historia literaria francesa donde la prensa se posicionó, por momentos, en disputa contra las decisiones políticas. La crítica como uso público de la razón adquirió, con la novela de folletín, un medio adecuado para circular ideas contra el poder.

El objetivo del artículo es elucidar algunas de las condiciones históricas e intelectuales que propiciaron que la novela de folletín colaborara con la aparición del intelectual público. Para tal fin, el artículo rastrea, en algunos textos literarios del siglo XIx francés, algunas obras historiográficas y de estudios referentes a la aparición del intelectual público, la correlación entre la historia literaria y la novela de folletín como medio de divulgación política y literaria. Al recuperar las investigaciones previas que han dado cuenta de la aparición de la novela de folletín y el tipo de lector que produjo, es posible exponer la relación entre la prensa y la novela para mostrar el devenir del intelectual del novelista decimonónico.

La hipótesis de este artículo es que la novela de folletín favoreció las condiciones materiales y simbólicas para la aparición del intelectual al constituirse como un foro público donde se expresaban los lineamientos éticos del escritor. El espacio de la prensa, donde se publicaban las novelas de folletín, incentivó el periodismo político de los autores. Por tal razón, el motivo de fondo de este artículo es profundizar y problematizar las razones históricas y literarias de la formación de la figura del intelectual público. La 
metodología del artículo consiste, principalmente, en un análisis social de algunos textos literarios, cuyo énfasis radica en la historia de la literatura nacional como historia de las prácticas de escritura. En particular, el artículo instrumenta una aproximación historicista a la intervención pública del novelista Émile Zola. Con este método se realiza un análisis socio-histórico de la novela de folletín y, al mismo tiempo, de las implicaciones políticas y literarias del caso Dreyfus. Por consiguiente, la metodología rastrea las condiciones sociales del campo literario para probar cómo los fenómenos literarios son efecto, en ocasiones, de profundas transformaciones materiales. El uso de esta metodología permite mostrar la relevancia que tuvo la novela de folletín en la formación del intelectual público decimonónico.

Entre los investigadores que han estudiado el tema de la novela de folletín, sus características y relevancia dentro de las temáticas novelísticas posteriores se encuentran Beatriz Molina, ${ }^{1}$ Dominique Kalifa, ${ }^{2}$ Laura Suárez de la Torre ${ }^{3}$ y Marie-Eve Thérenty. ${ }^{4}$ Para estos investigadores, la novela de folletín fue un fenómeno mediático que culminó en la construcción de un nuevo género narrativo: los misterios urbanos. El aporte más relevante de este tipo de novelas lo ha constituido la identificación del imaginario popular que se diseminó como parte de la cultura francesa. No obstante, las investigaciones previas no han analizado suficientemente la transformación material de las novelas de folletín ni las repercusiones del género de los misterios en la formación del intelectual público. Asimismo, el impacto de la prensa francesa en el siglo xix y la construcción de los nuevos públicos lectores ha sido estudiado por Edmund Birch, ${ }^{5}$ Christophe Charle, ${ }^{6}$ Jeremy Jennings, ${ }^{7}$ Marie-Pierre Le $\mathrm{Hir}^{8}$ y Martyn Lyons. ${ }^{9}$ Para ellos, la prensa francesa fue originariamente un fenómeno mediático que se centró en la publicación y distribución de femilletons. De modo que la circulación del periódico francés durante el siglo XIX estuvo en estrecho vínculo con la producción literaria; sin

1 Hebe Beatriz Molina, Cómo crecen los hongos: la novela argentina entre 1838 y 1872 (Buenos Aires: Teseo, 2011).

2 Dominique Kalifa, Los bajos fondos. Historia de un imaginario (Ciudad de México: Instituto Mora, 2018).

3 Laura Suárez de la Torre, "Estudio introductorio", en Tras las huellas de Eugenio Sue. Lectura, circulación y apropiación de Los misterios de París (Ciudad de México: Historia/Instituto Mora/Conacyt, 2015).

4 Marie-Eve Thérenty, "Los misterios urbanos en el siglo xix: un primer episodio de la mundialización mediática", en Tras las huellas de Eugenio Sue, 27-54.

5 Edmund Birch, Fictions of the press in nineteenth-century France (Cambridge: Palgrave, 2018).

6 Christophe Charle, Los intelectuales en el siglo XIX. Precursores del pensamiento moderno (Madrid: Siglo XXI, 2000).

7 Jeremy Jennings, Intellectuals in twentieth-century France. (Nueva York: Palgrave Macmillan, 1993).

8 Marie-Pierre Le Hir, "Stendhal et l'invention de l'intellectuel", Humanidades: revista de la Universidad de Montevideo, $\mathrm{n}^{\circ} 1$ y 2 (2007): 22-23.

9 Martyn Lyons, Readers and society in nineteenth-century France (Nueva York: Palgrave, 2001). 
embargo, aunque tales investigaciones explican la influencia de la prensa en la creación de nuevos lectores, una de sus deficiencias compartidas consiste en que no destacan el tipo de literatura que contenía la novela de folletín. Ni las investigaciones acerca de la novela de folletín ni los estudiosos sobre la prensa francesa han estado interesados en mostrar el impacto de este tipo de textos en la aparición del intelectual público en Francia. Este artículo intenta cubrir esta ausencia. Por último, el caso Dreyfus y la circulación de la prensa ha sido analizada de manera precisa por María de Gracia Caballos Bejano, ${ }^{10}$ Diana Hallman, ${ }^{11}$ Julie Kalman, ${ }^{12}$ Pascal Ory, ${ }^{13}$ Shlomo Sand ${ }^{14}$ como un caso de xenofobia en la Francia decimonónica que dividió a la población entre los que se nombraron «intelectuales» y los que despreciaron el adjetivo, pero pocos se han concentrado en las condiciones literarias de este tipo de intervenciones públicas.

Por lo anterior, el aporte de la investigación consiste en relacionar dos objetos de estudio que han estado vinculados entre sí, pero que pocas investigaciones han dado cuenta: la novela de folletín como el soporte material del aparición del intelectual público. Aunque las investigaciones anteriormente nombradas han destacado el caso Dreyfus como el origen de la aparición del intelectual, pocos destacan que el trabajo literario del escritor Émile Zola en la prensa es el resultado del fenómeno mediático que las novelas de folletín habían conseguido con el paso del tiempo. De manera que uno de los aportes de este artículo consiste en mostrar en qué medida la novela de folletín generó un tipo de escritor comprometido con la sociedad que, para cuando aconteció el caso Dreyfus, ya tenía el medio idóneo para plasmar sus demandas políticas. Al interpretar el caso Dreyfus como un momento fundacional de la aparición del intelectual decimonónico, no debe olvidarse que fue la posición política de un novelista — en este caso de Zola- quien defendió la libertad de prensa, delineó las conductas éticas del escritor e identificó al «pueblo» como su público lector.

Finalmente, el artículo está dividido en tres partes. La primera profundiza la relación entre las publicaciones de la novela de folletín y el tipo de escritura

10 María de Gracia Caballos Bejano, “El ‘affaire’ Dreyfus”: un caso de xenofobia y antisemitismo en los albores del siglo xx. Implicaciones políticas y literarias en la prensa francesa”, Philologia hispalensis 16, no 1 (2002): 50-59.

11 Diana R. Hallman, Opera, Liberalism, and Antisemitism in Nineteenth-Century France (Cambridge: Cambridge University Press, 2002).

12 Julie Kalman, Rethinking Antisemitism in Nineteenth-century France (Cambridge: Cambridge University Press, 2010).

13 Pascal Ory y Jean-François Sirinelli, Les intellectuels en France de l'affaire Dreyfus à nos jours (París: Armand Colin, 1986).

14 Shlomo Sand, ¿El fin del intelectual francés?: De Zola a Houellebecq (Madrid: Akal, 2017). 
literaria que genera este soporte literario. La segunda parte contextualiza el impacto público de la novela de folletín y de cómo este tipo de textos generaron las condiciones para la aparición del intelectual público. La tercera parte demuestra la relación entre el intelectual público y el caso Dreyfus, particularmente de la participación del escritor Émile Zola en la polémica generada por la censura estatal.

\section{«Mon cher Sue... TH. Burette»: la novela de folletín y la masificación literaria}

Como ha escrito el historiador Roger Chartier, el desarrollo de la prensa francesa tiene dos momentos: el decenio de 1840 y el de 1860. Mientras que en el primero, los costos de los periódicos bajaron y se publicaron los primeros feuilletons; en el segundo decenio los avances tecnológicos, como el ferrocarril o el correo, permitieron la distribución masiva del periódico que concluyó en el aumento de los lectores. ${ }^{15}$ La división histórica de Chartier sobre la difusión de la prensa en la vida cotidiana resulta necesaria para estudiar el proceso de alfabetización en Francia, sin embargo, omite el hecho de que, desde el primer momento, el periódico está integrado a la cultura de la literatura. En el primer decenio, autores como Eugène Sue, Honoré de Balzac, Jules Verne, Alexandre Dumas publicaron novelas por entregas en diversos periódicos con gran éxito monetario y aumento de lectores. Esto implicó que la novela folletín tuviera más relevancia histórica y editorial de la que supuso Chartier, ya que las publicaciones de libros estuvieron relacionadas al éxito comercial de la prensa. Un periódico con muchos lectores supuso una novela de folletín con mayor divulgación. La publicación masiva de feuilletons en los diarios evidencia que, por primera vez en la historia, las novelas por entregas no estaban dirigidas a un grupo letrado e influyente en el ámbito cultural, sino a un nuevo grupo social surgido en el siglo XIx: la sociedad asalariada, casi siempre de bajo nivel cultural, que emigraba a la ciudad con el objetivo de mejorar su situación económica.

Uno de los estudios más importantes del impacto editorial y cultural de la novela de folletín fue realizado por el investigador Martyn Lyons, quien 
concibió la producción masiva de este tipo de novelas como «cheap fiction». ${ }^{16}$ Esta atribución de lo que significó la novela de folletín es poco sensible a la importancia de estas publicaciones para la vida cultural y literaria de la Francia decimonónica, y por extensión, de la creación de la figura del intelectual. No porque la «cheap fiction» fuese económica, demerita su valor literario o su impacto en la circulación y producción de los libros.

La relación entre prensa y literatura devela un nuevo problema en la discusión crítica en dos registros: o la masificación del periódico produjo un tipo de público interesado en las nuevas formas de escritura $3 / 4$ el realismo como pretensión de lo real—o el nuevo público determinó, bajo el concepto de la moda actual, las características de la literatura por entregas. Ambas posiciones implican un acercamiento crítico dispar con respecto a la cuestión de la producción.

En relación con el primer caso, la discusión puede apoyarse en las decisiones editoriales y periodísticas para diferenciar lo verdadero de lo falso en la novela como un sentido que instaurase la responsabilidad social y, de ese modo, esparciese los valores de la época: ${ }^{17}$ la libertad de expresión o la moral política, familiar y social. La primera compilación de Les Mystères de Paris de Eugène Sue que se realizó el $1^{\circ}$ de julio de 1843 prueba cómo el escritor tiene el deber civil de reflejar la realidad de su tiempo. ${ }^{18}$ De igual modo, la correspondencia del escritor Gustave Flaubert y George Sand, entre otros, evidencia los temas de la verdad y el lenguaje para reflejar la realidad de la época. ${ }^{19}$

16 Lyons, Readers and society, 1.

17 La crítica literaria Hebe Beatriz Molina, dice al respecto: «No obstante, el periodista parisino no se propone destrozar la novela; antes bien, diferencia una serie de categorías, para poder clasificarla. Primero distingue dos suertes de verdades, como dos clases de realidades. [...] En segundo lugar, presenta las dos fases de lo falso: la que ataca la buena verdad y la que nos aparta de la mala. [...] Esta visión dicotómica entre lo que es y lo que debe ser aplica también al quehacer del escritor: este tiene libertad de opinión pero esta libertad está limitada por la moral y por su responsabilidad social [...], el honon». Molina. Cómo crecen los hongos, 48.

18 En la impresión de 1843 se incluyeron dos cartas del historiador y autor Jean Baptiste Théodore H. Burette, amigo de Sue; la primera de éstas fue un elogio al lenguaje utilizado en la novela, ya que éste accedía a los bajos fondos de la sociedad parisina para revelar los misterios ocultos. El patois representado en la obra de Sue no era otro que el de la Corte de los Milagros, el dialecto del crimen: «c'est une espèce de patois que les parias du crime ont inventé pour se reconnaitre en dehors de la société». T.H. Burette, [Carta de junio 16 de T.H. Burette a Eugène Sue], en Eugène Sue, Mystères de Paris (París: Librairie de Charles Gosselin, 1843), II. El escritor, cuyo papel fue convertirse en el espejo de la realidad, encontró en el patois la manera de adentrarse en el corazón de la sociedad para devolverle su propio reflejo, de manera que la literatura de misterios adquirió la imposición de la mímesis como pacto de verosimilitud.

19 Gustave Flaubert, Razones y osadías (Buenos Aires: Edaf, 1997). 
El segundo caso puede apoyarse en la carta posterior de T.H. Burette, amigo de Eugène Sue, que se incluyó en la impresión de 1843 y que resultó en la autorización del historiador para que Sue y su editor pudiesen publicar su primera carta en la introducción de la obra. La impresión y publicación de Les Mystères evidencia que lo que comenzó como novela de folletín se convirtió en libro tras el éxito en la prensa. Más aún, las ilustraciones incluidas fueron pronosticadas por Burette como el gran éxito comercial del momento:

Pour vous l'illustration n'est qu'on accessoire qui vient poliment offrir à votre libre une auréole dont il n'a nul besoin, fort qu'il est de lui-même, et peignant de main de maitre, avec une si grande vérité de couleur et de dessin, qu'il fait passer à l'état réel toutes les fantaisies de votre imagination. Mais la mode est là qui s'impose, et la mode a raison quand elle associe l'art à la littérature pour qu'ils se traduisent et se commentent l'un l'autre sans jalousie de métier. ${ }^{20}$

Para Burette, la moda quedaba exenta de las pretensiones autorales y respondía únicamente al gusto del público. El gusto del público determinó, tal como se verá más adelante, si los fenilletons se dividían por su producción y consumo en «novelas de folletín» o «novelas por entregas».

De cualquier modo, el dilema — si la masificación del periódico produjo un nuevo tipo de público o el público determinó las nuevas formas de la literatura - resulta indisoluble; concentrarse en el falso dilema no soluciona el problema crítico: cómo fue que los procesos productivos dieron lugar al público lector decimonónico y qué implicaciones literarias tuvo la expansión de la prensa. Para responder lo anterior, es necesario mostrar que la masificación de la prensa engendró un nuevo tipo de lector-consumidor: primero, por el abaratamiento de costos; segundo, por la creciente alfabetización, y tercero, por la pretensión de verdad que se instauró como responsabilidad social.

Las razones históricas que fomentaron la novela de folletín son relevantes para mostrar la relación entre este tipo de publicaciones y el tipo de escritores que albergaba. En aquel momento, los periódicos competían por ganar mayor número de suscriptores. La innovación consistió en la creación de una parte final, conocida como «folletín», en donde se incluyeron capítulos de novelas. Las novelas publicadas en la prensa se dividieron en «novelas de folletín»y «novelas por entregas»: las primeras se publicaban en partes por un autor reconocido como un suplemento fijo en los periódicos. Las segundas, de autores menos reconocidos, dependían del impacto con el público; por tal 
razón, variaban su extensión. La mayoría de las veces, la publicación de las novelas por entregas era resultado del trabajo de dos o más autores y, por ello, eran inevitablemente anónimas. Además, en ambas existieron temas recurrentes y poco variados como la orfandad de los personajes principales, la pobreza — recompensada después con la fortuna—, el rescate del protagonista y el encuentro con lo perdido: el trono, la madre, el padre. La elección de temas evidencia que el interés del editor se centró no en el resultado literario, sino en la ventaja económica de la venta. El primer periódico en introducir este modelo fue Le Presse en $1842 .{ }^{21}$ Posteriormente, otros diarios como Le Siècle, Journal des Débats, ${ }^{22}$ Petit Journal ${ }^{3}$ y Le Constitutionne ${ }^{4}$ le siguieron a la divulgación de novelas de folletín.

La serie de novelas incrementó la circulación de la novela de folletín. Por ejemplo, en 1844, Le Constitutionnel aumentó la circulación al publicar en serie Le Juif errant de Sue. Más tarde, en 1868, la publicación de Le crime d'Orcival de Émile Gaboriau en Petit Journal superó los 400.000 ejemplares y colocó a la novela de folletín en el número uno en ventas, lo que esboza la conexión entre la circulación del periódico y la producción literaria. El aumento en la circulación de la prensa abarató los costos de compra. En la primera mitad del siglo xix, en 1836, La Presse y Le Siècle redujeron el precio de las suscripciones de 80 a 40 francos. Más tarde, en el número del 18 de mayo de 1841, La Presse colocó un anuncio para vender el ejemplar La physiologie du flâneur de Louis Huart en un franco..$^{25}$ Además, en 1838 el editor Gervais Charpentier — quien después elaborará la serie La Bibliothèque Charpentier que incluyó autores como Honoré de Balzac, Víctor Hugo o Alfred de Mussetvendió libros más económicos cuando transformó los formatos originales en tamaños pequeños y accesibles, a un costo de 3.5 francos, para atraer a un público mayor. ${ }^{26}$ Martyn Lyons escribió al respecto que, con la disminución

21 Cfr. Feuilleton titulado Hervé. (París), 13 de diciembre, 1842. Biblioteca Nacional de París, https://gallica.bnf. fr/ark:/12148/bpt6k429063z/f1.image.

22 Cfr. Primera publicación del feuilleton Les mystères de Paris en el periódico Journal des Débats. (París), 19 de junio, 1842. Biblioteca Nacional de París, https://gallica.bnf.fr/ark:/12148/bpt6k4458735/f1.image.

23 Cfr. Carta a los lectores del Petit Journal titulado Fenilleton du Petit Journal en la que se presenta la iniciativa de publicar novelas de folletín. (París), 31 de enero, 1863. Biblioteca Nacional de París, https://gallica.bnf.fr/ark:/12148/ bpt6k588113x?rk=21459;2.

24 Cfr. Anuncio publicado en el periódico Le Constitutionnel, Journal du commerce, politique et littéraire sobre la política de la nueva administración a reducir el precio de los ejemplares (40 francos en París y 48 francos en los departamentos) y publicar, al menos, 25 fenilletons por mes (París), 23 de marzo, 1844. Biblioteca Nacional de París, https://gallica. bnf.fr/ark:/12148/bpt6k666675g/f1.image.

25 Cfr. Anuncio titulado Physiologie du flâneur en La Presse (París), 18 de mayo, 1841. Biblioteca Nacional de París, https://gallica.bnf.fr/ark:/12148/bpt6k62352r.texteImage

26 Anne O’Neil-Henry, Mastering the Marketplace. Popular literature in nineteenth-century France (Nebraska: University of Nebraska Press, 2017), 6. 
del formato y el abaratamiento en los costos, Charpentier revolucionó la producción editorial, pues el libro ya no estuvo destinado a bibliotecas o gabinetes de lectura:

In the 1830s, Charpentier revolutionized fiction production by compressing the text into a single, small-format volume, instead of ventilating it excessively to create several volumes for a secure market of libraries and cabinets de lecture. This made novels cheaper and more portable. ${ }^{27}$

Sin embargo, la revolución de Charpentier no fue la producción de libros en formatos pequeños, sino la creación de una editorial que surgió en la primera mitad del siglo xIx y se extendió a la segunda mitad con ejemplares cada vez más económicos. En 1863 salió a la venta un formato pequeño y económico, a tan sólo 5 céntimos, que se tituló Le Petit Journal. Para 1887, la tirada de Le Petit Journal — 950.000 ejemplares_ lo posicionó como el periódico más grande que no se vendió entre los suscriptores sino en puntos de venta. Sin duda, fue un gran competidor del Journal des Débats, periódico que extrajo múltiples ganancias con la publicación de Les Mystères de Paris, o del Le Siècle cuando en 1844 publicó como contrapropuesta Les Trois Mousquetaires de Dumas.

Un ejemplo paradigmático de la novela de folletín fue la novela de misterios. La aparición de Les Mystères de Paris fue todo un acontecimiento que dejó tras de sí un legado literario conocido actualmente como «novelas de misterios». Entre 1840 y 1850, las novelas de misterios ${ }^{28}$ fueron difundidas gracias a la creación de

\section{Lyons, Readers and society, 10.}

28 El género «misterios urbanos» recibió su nombre después que las publicaciones — las cuales respondían a una determinada zona geográfica (Francia) — impactaron a otros sitios del mundo: Madrid, Londres, Nueva York, México y Argentina. Los escritores latinoamericanos, debido a su afrancesamiento, tuvieron mayor apertura a la novela de misterios, aunque fueron duramente censurados. En Argentina, el periódico El Orden, dirigido en 1855 por Félix Frías y Luis Domínguez bajo el gobierno de Juan Manuel de Rosas, prohibió las nuevas novelas francesas. Entre los acusados se encontraron los nombres de Alexandre Dumas, Eugène Sue y George Sand. Cfr. Beatriz Molina, Cómo crecen los hongos. Además, Laura Suárez de la Torre explica que la novela de misterios tuvo un alcance mundial que la convirtió en un fenómeno mediático: «los misterios urbanos se constituyeron en un género literario que muy pronto se leyó, circuló, se exportó, se tradujo y se apropió en el mundo. De ahí que pueda considerarse como el primer fenómeno mediático en la historia al dejar de ser una publicación específica de un lugar, Francia, e impactar a Europa y de allí a América». Suárez de la Torre, "Estudio introductorio", 2. Algunas de las novelas de misterios que siguieron a la de Eugène Sue fueron Los misterios de Madrid escrita en 1844 por Martínez Villergas; Les mystères de Londres escrita en el mismo año por Paul Feval; Les Mystères du Palais-Royal de Xavier Montépin, escrita en 1845; Los misterios del Plata de Juana Manso, completada y corregida por el editor en 1899, pero escrita entre 1846 y 1850, y Los misterios argentinos de Manuel Olascoaga, escrita aproximadamente en 1865. En 1867, Zola publicó en Le Messager de Provence su novela de misterios: Les Mystères de Marseille. Entre 1849 y 1856, el mismo Sue escribió una nueva saga de misterios que tituló Les mystères du peuple. Para el teórico literario David Pike, tanto en Francia como en otras partes del mundo, las novelas de misterios se popularizaron debido al imaginario popular de los bajos fondos que circundaba. Cfr. David L. Pike, Metropolis on the Styx. The Underworlds of Modern Urban Culture, 1800-2011 (Nueva York: Cornell University Press, 2007). 
Les mystères de Paris y a los periódicos de la época. Las notas de Anne O’NeilHenry apuntan a que entre 1842 y 1850, 60.000 lectores compraron Les Mystères y hasta 800.000 la consumieron. ${ }^{29}$ Así, el éxito mercantil contribuyó al proceso de alfabetización pues, según lo que Martyn Lyons señala, el 47\% de la población masculina y sólo el $27 \%$ de la población femenina podían leer; mientras que, a finales del siglo xix, las cifras aumentaron considerablemente tanto para las mujeres como para los hombres. ${ }^{30}$

Por un lado, la novela de folletín desdibujó la frontera entre la alta cultura y la cultura popular por medio de la introducción de un lenguaje coloquial como instrumento literario: el patois. La diferencia entre lo oral y lo escrito fue una de las tantas perspectivas que la Revolución diseminó como ideales ilustrados por toda Francia y que propició que múltiples amigos de la Constitución estuviesen dispuestos a destruir su patois y adoptar el francés como un sacrificio, excluyendo así al campesinado y marcando una división entre el «ello» (la oralidad, lo inculto) y el «nosotros» (la escritura, lo culto). ${ }^{31}$

Si la lengua muestra códigos culturales, sociales e incluso normativos de los hablantes, las variaciones dialectales o el argot no son la excepción desde el siglo XVIII, la lengua se comprendió como pintura de la sociedad. El abbé Grégoire $^{32}$ al distinguir los campos — lengua y sociedad—en el Rapport sur la Nécessité, mostró que la lengua determina y configura a la sociedad. Destruir el patois fue sólo el primer paso en una cadena de exclusiones que aseguraban el triunfo de la Revolución. El patois fue considerado como el lenguaje de un «otro» que corrompía los ideales ilustrados. ${ }^{33} \mathrm{Un}$ «otro» campesino que comprendió una separación social y no solamente lingüística del «nosotros»: los que habitan el espacio urbano. Por tal razón, la división entre los que podían o no leer sirvió como mecanismo de poder durante el siglo XVIII. Sin embargo, en el siglo XIX, algunas de las novelas de folletín introdujeron el argot como elemento central de su política literaria y, con ello, posibilitaron la revolución del pensamiento. Un ejemplo de las novelas que aprovecharon el argot fue

\footnotetext{
29 O’Neil-Henry, Mastering the Marketplace, 89.

30 Lyons, Readers and society, 1.

31 Cfr. Michel De Certeau, Una política de la lengua (Ciudad de México: Universidad Iberoamericana, 2008), 30.

32 Abbé Henri Grégoire (1750-1831), líder revolucionario francés, elaboró un cuestionario que utilizó como instrumento para determinar las características principales del patois y las diferencias entre éste y el francés. El informe sobre el estado de la lengua francesa fue titulado como Rapport sur la Nécessité et les Moyens d'anéantir les Patois et d'universaliser l'usage de la langue française (Informe sobre la Necesidad y los Medios para destruir las lenguas y de universalizar el uso de la lengua francesa). Posteriormente, la Encyclopédie, ou Dictionnaire raisonné des sciences, des arts et des métiers de 1778 en la página 992, asoció el patois con un lenguaje corrompido.
}

33 De Certeau, Una política de la lengua, 30. 
Les Mystères de Paris. T.H. Burette, amigo de Sue, calificó al patois utilizado en la novela como un «dialecto del crimen» que develaba al lector culto el código lingüístico hablado en la Corte de los Milagros. Pese a las interpretaciones de Burette, la introducción del patois en la literatura no significó únicamente el dialecto del crimen, sino la inclusión en el campo literario de un público lector excluido en la Revolución: el retorno de lo plebeyo en la República de las Letras. ${ }^{34}$

Por otro lado, la novela de folletín, a su vez, describió ciudades y personajes - como las fisiologías ${ }^{35}$ de Honoré de Balzac o de Louis Huart- que permitieron que los lectores comprendieran espacios urbanos y personajes que no habían sido explorados y categorías sociales que cambiaban constantemente. ${ }^{36}$ Tanto las fisiologías como las «novelas de misterios» que estaban contenidas en las novelas de folletín y sirvieron a los lectores para comprender el mundo que se les había ocultado: el primero, por medio de fisiologías narrativas, y el segundo, mediante la representación del crimen. ${ }^{37}$ Esto supuso que el escritor asumiera el lugar y la voz de los sujetos que habían sido silenciados como objeto de representación literaria. A diferencia de la novela burguesa, representada por Flaubert, la novela de folletín, al estar dirigida a un público más amplio — prácticamente cualquier lector- supuso la formación tanto de un nuevo público como de un nuevo tipo de escritor. El escritor no estaba preocupado tanto por la calidad literaria del texto como por permanecer en el gusto del público de prensa. El público, en cambio, valoró personajes literarios que compartiesen su lenguaje, sus problemas, sus fenómenos de marginalización del momento y, de manera más precisa, sujetos

34 En la actualidad, la introducción del uso del habla coloquial en las novelas es un dispositivo ampliamente utilizado para atraer a las masas. Al respecto Michael Warner escribió «La cultura de masas adorna su discurso de frases pegadizas que lo saturan de un habla informal solo porque dichos latiguillos están primeramente tomados de los textos de masas». Michael Warner, Públicos y contrapúblicos (Barcelona: Universidad Autónoma de Barcelona, 2018), 63. El impacto de los medios masivos en el público contemporáneo es estudiado bajo sistemas de medición de rating: número de audiencia, de suscriptores, de televidentes o de oyentes. No obstante, para analizar la circulación y las influencias del discurso de la prensa en los lectores decimonónicos es indispensable estudiar las discusiones de la época, el aumento de las poblaciones alfabetizadas e, incluso, las transformaciones de los feuilletons a libros. De modo que una novela por entregas exitosa no tardaba en transformarse en libro.

35 Anne O’Neil-Henry analiza la influencia de los textos panorámicos, como las fisiologías, en el imaginario social urbano y sus implicaciones en el campo literario. Cfr. O’Neil-Henry, Mastering the Marketplace.

36 O’Neil-Henry, Mastering the Marketplace, 27.

37 La estudiosa en novelas de misterios, Marie-Eve Thérenty, explicó que el imaginario del crimen decimonónico se evidenció por medio de descripciones espaciales que surgieron como protagonistas de la novela: la urbanidad, el crimen, las identidades sociales. Thèrenty, "Los misterios urbanos", 31. Una de las características fundamentales de las novelas de misterios fue el espacio urbano que creaba atmósferas de misterio y personajes marginales que no habían sido retratados anteriormente por la literatura. 
similares a su propia condición. Al respecto, un testimonio de la época ilustra esta relación: la carta de T.H. Burette a Eugène Sue.

Vous pouvez avoir toutes les jouissances de la vie, et vous troublez celles des autres par l'étalage de misères qui ne peuvent vous atteindre; vous frappez à la porte des prisions, vous leur demandez leurs plus terribles secrets; vous visitez le chenil du pauvre, vous entrez gaillardement dans les bouges de la Cité; vous êtes bon prince, comme votre Rodolphe [...] Vos héros sont des voleurs, des assassins, des femmes perdues, et vous faites descendre à leur niveau les gens du monde qui, dans leur perversité, n'ont point l'excuse de la misère et de l'ignorance. ${ }^{38}$

Como puede notarse, este intercambio epistolar entre Burette y Sue muestra el impacto público de la novela de folletín. Un impacto que prueba en qué medida uno de los objetivos definitivos o finales de la novela de folletín fue la de retratar a los sujetos, las instituciones, las costumbres y las prácticas de la Francia de la época, razón por la cual es un preámbulo del realismo literario. ${ }^{39}$ En este caso, el amigo de Sue le reclama por retratar literariamente asesinos, prostitutas y, quizá lo más relevante, es que lo acusa, al hacer esta operación literaria, de bajarse al nivel de éstos personajes. En lugar de indicar que estos sujetos marginalizados «suben» la escala de representación social y literaria; Burette lo acusa por la operación ilegítima.

En definitiva, el historizar las prácticas de lectura en la sociedad decimonónica permite comprender las relaciones de clase, de dominación y las prácticas de producción editorial que posibilitaron la expansión de un tipo de literatura de mayor divulgación. Por lo tanto, la novela de misterios como el máximo exponente de la novela de folletín permitió que el novelista adquiriese una nueva función intelectual: retratar a los no sujetos de representación y adquirir para sí un compromiso, ético y político, con algunos sectores de la sociedad. No es extraño, finalmente, que en 1843, T.H. Burette nombrase a Eugène Sue como un historiador poeta (bistorien poète) por la labor de escritura que une el arte y la historia en Les Mystères de Paris. Pronto, muchos escritores, entre ellos Émile Zola o Jules Verne comenzarán a publicar algunas de sus obras en folletines con la misma finalidad que Sue: convertirse en los historiadores de su tiempo.

38 Burette, T.H. [Carta de junio 16 de T.H. Burette a Eugène Sue], III.

39 Para más información sobre los elementos de la novela realista, Cfr. Jocelyn Benoist, Éléments de philosophie réaliste (París: Librairie Philosophique, 2011). 


\section{«Toutes ces atrocités, toutes ces misères dont vous vous êtes fait l’historien poète»: el devenir público del intelectual}

El surgimiento del intelectual público siempre mantuvo una relación directa con la institución literaria. Como ha probado Pascal Ory en Derniéres questions aux intellectuels, el intelectual público en Francia es «un homme du culturel mis en situation d'homme du politique» ${ }^{40}$ [un hombre de cultura colocado en la posición de un hombre de política]. Esto significa que la noción «intelectual público», por lo menos en la Francia decimonónica, es una contradictio in adjecto. No hay intelectual en Francia que no aspire a tener influencia en la esfera pública. ${ }^{41}$

En consecuencia, el novelista, en general, adoptó la función de intelectual para defender el interés del público lector. Como portavoz del pueblo, el novelista amparado en el soporte del folletín ocupó el sitio de intelectual público. Esta transformación del escritor fue resultado, entonces, de tres procesos históricos. Primero, tras la aparición de la literatura como reflejo de la «verdad social»: un tipo de información sobre los acontecimientos que autoriza al escritor a hablar en nombre de los que no poseen la letra; particularmente, sujetos invisibilizados como los mineros, los ladrones, las prostitutas, entre otros sujetos sub-representados. Segundo, la novela de folletín admitió un fuerte compromiso ético y pedagógico, puesto que el escritor entendió parte de su trabajo literario como un compromiso con las clases subalternas. Por último, este novelista que es simultáneamente un intelectual fomentó un imaginario distinto al de la república literaria articulada por la aristocracia. ${ }^{42}$

Para explicar la correlación entre compromiso social y novela de folletín es necesario describir la importancia de la novela científica-pedagógica: un tipo de novela que tenía la misión de informar sobre los descubrimientos científicos de la época. Por consiguiente, el desarrollo de la novela científica-pedagógica

\footnotetext{
40 Pascal Ory, dir., Dernières questions aux intellectuels (París: Olivier Orban, 1990), 24. Para más información sobre el tema, Cfr. Ory y Sirinelli, Les intellectuels en France.

41 Cfr. Sand, ¿El fin del intelectual francés?

42 Durante el siglo XIx, la aristocracia fue una clase social en decadencia, como también una categoría que refirió la función político-económica perteneciente al ancien régime. La burguesía, por el contrario, fue una clase social dominante del capitalismo que se sublevó contra la aristocracia. Dentro de ambas clases existieron individuos cuya actividad intelectual repercutió en el imaginario de la aristocracia como clase pensante. Por el contrario, los vínculos entre los burgueses y el naciente capitalismo produjeron el imaginario de la burguesía como clase empresarial.
} 
debe analizarse en relación con los medios de producción que la publicaron y con los textos científicos que condicionaron su aparición en la prensa.

Uno de los máximos exponentes de la novela científica-pedagógica fue Jules Verne. Sus novelas se ajustaron a la economía del medio vendiéndose por entregas en diversas revistas científicas. Mucho antes de que su editor, Pierre Jules Hetzel, vendiera la colección de sus cuentos Voyages extraordinaires, los textos de Verne fueron publicados en partes por el Magasin d'éducation et de récréation, Le Journal des débats, Le Temps, Le Soleil, Le Journal, Le Musée des Familles, La Science illustrée, Le Figaro y Les Mémoires de L'Académie d'Amiens. ${ }^{43}$ Aunque la biografía de Verne es relevante para la historia literaria francesa, lo importante para estudiar el proceso literario como práctica pedagógica es trazar la historia de las decisiones editoriales de Hetzel para la revista Magasin d'éducation et de récréation. En principio, la publicación se dirigió a todas las edades como el proyecto de una biblioteca durable con títulos consecutivos durante todo un año: el inicio de una política educativa.

C'est une continuité dans l'instruction, certains titres se voyant suivis pendant une année complète. La revue échappe ainsi à la péremption propre au périodique, consommé puis oublié. Elle se conserve pour constituer une bibliothèque durable. Hetzel pose cet objectif comme une ambition décisive de sa revue envisagée comme une forme d'encyclopédie progressive, ordonnée et approfondie. ${ }^{44}$

La decisión editorial de un proyecto enciclopédico incluía la ficción de Verne en relación con los descubrimientos científicos del momento. El novelista es la herramienta que populariza el conocimiento entre los lectores estereotipados que el periodista ha creado: lectores aficionados a la ciencia, amateurs de los descubrimientos y de las novelas de aventuras. El novelista, Prometeo del discurso científico popular, llevó los avances del siglo del progreso a un público cada vez más amplio. El añejo ideal ilustrado comenzaba a materializarse históricamente.

Una implicación de los usos sociales de la novela pedagógica consistió en acelerar el proceso productivo de las publicaciones masivas. Con el incremento editorial, la necesidad de escritores fue imperante: se abrió un campo fértil

43 Claire Barel-Moisan, "Du Magasin à La Science illustrée. Hybridation du roman vernien dans l'écosystème de la revue", en Jules Verne et la culture médiatique. De la presse du XIX siècle au steampunk, eds. François-Emmanuël Boucher y Maxime Prevost (Québec: Presse de L’Université Laval, 2019), 38.

44 Barel-Moisan, "Du Magasin à La Science illustrée", 42. 
para la aparición del intelectual público. Este novelista comprometido con la realidad social admitía tres orientaciones para su práctica literaria: un autor comprometido socialmente, un portador de la «verdad» y un guía del pueblo. La voz del intelectual ya no callará más. Al mismo tiempo, el escritor de novelas de folletín mantuvo un ethos público motivado por la masificación de la prensa, puesto que tal masificación implicó un nuevo tipo de público. El escritor de esta época estuvo altamente condicionado por la aparición de la prensa, razón suficiente para mediar entre el público y la sociedad de su tiempo en la medida en que visibilizó temáticas que no existían en el registro literario. A su vez, este tipo de novelista develó espacios sociales que habían sido desplazados del centro de la ciudad y cumplió con un compromiso social de mostrar la verdad históricamente relevante para el pueblo. El escritor decimonónico, por consiguiente, estuvo en condiciones de acotar el statu quo a la aristocracia al adquirir la responsabilidad de criticar la sociedad de su época y reflejar las problemáticas sociales que vivía la mayor parte de la población. La responsabilidad social del escritor de masas se evidenció en la publicación de novelas sociales que, aunque intentaron despolitizarse en el Segundo Imperio, siguieron publicándose.

Un ejemplo del intento de politización literaria del Segundo Imperio fueron las novelas de Émile Zola. Como han defendido múltiples investigadores ${ }^{45}$ la mayoría de las novelas de Zola pueden ser interpretadas como novelas con un fuerte compromiso social. Por ejemplo, la novela $L$ 'Assommoir cumplió con el objetivo de representar sujetos marginales que no habían sido lo suficientemente incorporados a la literatura durante la primera mitad del siglo XIX: reflejó las formas de vida subalternas por medio del uso del lenguaje de los arrabales o por la introducción de las costumbres en los barrios periféricos de París: Goutte d'Or ${ }^{46}$ En efecto, el barrio de Goutte d'Or es uno de los objetos de representación del autor. Zola retrató el drama social del obrero que visita las tabernas. La genealogía de la rama bastarda de los Macquart, que delineó a lo largo de las veinte novelas, constituye la saga de una familia

\footnotetext{
45 Sophie Béroud y Tania Régin, eds., Le roman social. Litterature, histoire et mouvement (París: Les Éditions de l’Atelier, 2002); Alexandre Zévaès y Frederick Brown, Zola (Ciudad de México: Biografías Gandesa, 1958). Frederick Brown, Zola a Life (Baltimore and London: The Johns Hopkins University Press, 1996).

46 La Goutte d'Or fue también remodelado por Georges Eugène Haussmann (obtuvo el título de barón durante el imperio de Napoleón III, fue famoso por su trabajo en las renovaciones de la urbe parisina); desde el comienzo fue habitado por inmigrantes llegados de las provincias a París y, posteriormente, a finales del siglo xix, por inmigrantes del norte de África. El barrio quedó limitado al norte por la calle Ordener; al sur, por el Boulevard de la Chapelle; al este, por las vías férreas de la Gare du Nord y al oeste por el Boulevard Barbès.
} 
en el Segundo Imperio. ${ }^{47}$ Ante una larga jornada de trabajo que comúnmente duraba trece o catorce horas, sobrepasando así el límite legal que se había establecido en el decreto del 2 de marzo de 1848, la taberna se convirtió en el lugar de fuga y de disertación política, tanto de los personajes zolianos como del obrero decimonónico. En la taberna se fraguaron luchas comuneras y huelgas que Zola plasmó en numerosos artículos y pasajes novelísticos. ${ }^{48} \mathrm{La}$ documentación científica utilizada por el autor le permitió inventar personajes que retrataban a un grupo social invisibilizado que comenzaba a leer y a formar parte en las decisiones políticas de su tiempo.

Émile Zola no sólo fue un destacado novelista, sino que mantuvo una intensa actividad periodística. Este trabajo en la prensa le permitió mantener un doble registro literario: como el novelista que retrató a los sujetos marginalizados y como el escritor preocupado, cada vez de manera más intensa, por asuntos públicos. El caso más notable de esta intervención pública fue el caso Dreyfus y la pugna por la intelectualidad.

En la segunda mitad del siglo XIx, cuando la prensa ya está enteramente constituida y el escritor se rigió bajo las pretensiones de los editores y los lectores, la pugna por la libertad de pensamiento y de expresión fue la guerra por la intelectualidad. La publicación masiva del periódico fue el símbolo del siglo del progreso. Edmund Birch dirá al respecto que entre 1830 y 1880 acontece el advenimiento de la prensa de masas y, con ello, un nuevo régimen de lectura: incremento de lectores, imposiciones editoriales y temáticas para los escritores, una ética del escritor. ${ }^{49} \mathrm{El}$ nuevo régimen de lectura posibilitó el surgimiento de un intelectual concentrado en los problemas de la época. Incluso, puede decirse que el desarrollo del intelectual decimonónico es el resultado de un régimen de lectura determinado por el público burgués.

47 La rama bastarda de los Macquart la componen la lavandera Gervaise, madre, personaje de L'Assommoir; Claude Lantier, hijo, protagonista de la novela L'CEuvre; Étienne Lantier, hijo, protagonista de la novela Germinal; Jacques Lantier, hijo, protagonista de La Bête bumaine, y Anna Coupeau, la única hija, protagonista de Nana.

48 Desde 1871, Zola recreó sus experiencias de la comuna y su lucha en periódicos como La Cloche y Le Sémaphore de Marseille. Zola fue un cronista parlamentario de Versalles. Cfr. Recopilación de cartas de Zola de Patricia Carles y Béatrice Desgranges, en Émile Zola, La Commune 1871 (París: Chronos, 2018). Para describir a los obreros de la época, Zola estudió el uso del alcohol como una manera en que los obreros resistían jornadas largas y agotadoras. El tema del alcoholismo fue estudiado cuidadosamente por Zola en obras médicas; consultó diversos tratados de lengua popular, entre ellos el Dictionnaire de la langue verte. Argots parisiens comparés, de 1866, escrito por Alfred Delvau y el libro de Denis Poulot, Question sociale. Le Sublime ou le travailleur parisien tel qu'il est en 1870, et ce qu'il peut être. En lo que concierne a la psicología del obrero, revisó un artículo de Francisque Sarcey que se publicó en el Gaulois el 8 de febrero de 1870. Cfr. Zévaès, Zola, 71.

49 Edmund Birch, Fictions of the press in nineteenth-century France (Cambridge: Palgrave, 2018), 3. 
A lo largo de la historia, la palabra «intelectual» sufriría diversos cambios semánticos con base en las transformaciones políticas de la época. Mientras que, en 1889, Henry Bérenger propuso el término intellectuel como símbolo de elegancia estética y distinción social, una década más tarde Maurice Barrès utilizó el adjetivo intellectuel como un insulto para el general Dreyfus. El término «intelectual» no siempre gozó de buena fama ni tuvo el prestigio del siglo XX. Poco antes del uso peyorativo de Barrès, el 14 de enero de 1898, Georges Clemenceau, en L'Aurore, transformó el insulto en la ayuda que necesitaba Émile Zola para promulgar el Manifeste des Intellectuels. ${ }^{50} \mathrm{El}$ intelectual se presentó como un criterio de responsabilidad civil, pues la historia de los intelectuales decimonónicos es equivalente a la historia de la prensa escrita.

La recuperación de la palabra intellectuel por parte de Zola abrió una nueva época en la que el auge del intelectual público suponía un compromiso político de los escritores. El adjetivo «intelectual», entonces, se utilizó para los escritores en contra del gobierno. En contraste, los «anti-intelectuales» fueron escritores pagados, miembros de la Académie Française, que no tenían ningún interés por la defensa de los sujetos marginados. Al respecto de esta distinción, el historiador Christophe Charle elaboró una clasificación del intelectual decimonónico francés basado en la división en tres grupos. El primer grupo, los «anti-intelectuales», estuvo formado por Pierre Loti, Édouard Rod, Paul Bourget, François Coppée, Ferdinand Brunetière, entre otros. El segundo grupo fueron los escritores de vanguardia, los defensores del «arte por el arte», como Stéphane Mallarmé, Francis Vielé-Griffin, SaintGeorges de Bouhélier o Firmin Gémier, quienes intentaron deslindar el valor de la obra estética a las problemáticas sociales o políticas. Por último, el tercer grupo se identificó con el término «intelectual» y se constituyó por escritores y dramaturgos que escribían para el público de masas como Émile Zola, Octave Mirbeau, J. K. Huysmans o León Daudet. ${ }^{51}$ Naturalmente, aun cuando las intenciones de los autores «intelectuales» hubiesen estado divididas, en su carácter de portavoces del pueblo, los novelistas fueron mediadores, puentes, intermediarios que circulaban e intercambiaban información entre el pueblo y los problemas de su época.

Los intelectuales europeos tienen su propia historia nacional. Contrario a lo que sostiene Guillermo Zermeño Padilla, el concepto «intelectual» no

50 Le Hir, "Stendhal", 22-23.

51 Charle, Los intelectuales, 254. 
pertenece específicamente al siglo $x x,{ }^{52}$ a menos que, como más adelante matizará, se refiera específicamente al contexto hispanoamericano. La masificación de la prensa y la inserción del escritor en la vida pública trazaron, finalmente, los lineamientos del trabajo del intelectual decimonónico francés. Pese a que las pugnas políticas dividieron a los autores, su escritura se centró en un trabajo de intercambio de conocimientos entre el pueblo y su sociedad: definieron cuáles fueron los bajos fondos de la ciudad por medio del retrato epocal, denunciaron las injusticias y redefinieron los regímenes burgueses o aristócratas que impedían el acceso del pueblo a la lectura. Aun cuando Jules Verne, Léon Daudet o Pierre Loti desdeñaron el término intelectual, la prensa fue la condición de posibilidad para que sus ideas sobre la responsabilidad civil del escritor circularan entre el público lector de la prensa. La noción del intelectual dependió, entonces, del desarrollo histórico de la prensa, ya que el intelectual mantuvo el intercambio comunicativo entre los diversos sectores de la población francesa. Lo «intelectual», más que una postura política, fue la acción de transmitir conocimiento y las ideas sobre básicamente cualquier asunto literario o público. Por lo tanto, el problema de los intelectuales en la Francia decimonónica fue, además de un asunto político que problematiza la relación entre escritura y opinión pública, un problema epistemológico: el problema de cómo articular o hacer circular los conocimientos de manera vertical (entre los grupos letrados y el pueblo) y de manera horizontal (entre los grupos letrados). En definitiva, la conexión histórica entre los intelectuales, la prensa y los modos de representación letrada constituyen un capítulo crucial de la historia literaria francesa.

En conclusión, la visibilización de sujetos que no eran notables en la época fue el trabajo principal del intelectual público en condiciones de prensa, aun cuando el término intellectuel no se incorporó en el vocabulario hasta $1890 .{ }^{53}$ Bajo esta distinción, es posible postular que Eugène Sue, Jules Verne, Stendhal, entre otros, fueron novelistas que pueden ser leídos como intelectuales públicos.

52 Guillermo Zermeño Padilla, Historias conceptuales (Ciudad de México: El Colegio de México, 2017), 321.

53 Le Hir, "Stendhal", 22. 


\section{«¡Germinal! ¡Germinal!»: la cooperación del intelectual en la lucha antisemita}

El interés de los autores de novelas de folletín por la vida pública fue proporcional a la reorganización de un público lector interesado por los asuntos políticos de su época. ${ }^{54}$ Los soportes materiales fueron imprescindibles para la reorganización de lecteurs, spectateurs, auditeurs, que no concernieron únicamente a los grupos letrados de la sociedad pertenecientes al poder político. Con los escritores de novelas de folletín sucedió un proceso similar: conformaron un nuevo grupo letrado que utilizó el poder de la opinión pública para ejercer presión sobre órganos políticos. El ejemplo más paradigmático fue el caso Dreyfus y la injerencia de la prensa en asuntos de Estado. De 1894 a 1906, la prensa acompañó el proceso de condena del capitán Alfred Dreyfus y se dividió entre los que lo apoyaban y quienes lo rechazaban. El caso Dreyfus que, en el fondo fue un caso de xenofobia en un contexto militar, desató una polémica masiva en los soportes de la prensa, que ya gozaban de prestigio social gracias a la novela de folletín. Este hecho posibilitó que muchos escritores estuviesen involucrados en asuntos que concernían a la milicia, e incluso, al poder político.

El polémico caso comenzó el 22 de diciembre de 1894 cuando el Consejo de guerra francés inculpó de traición y condenó al capitán Alfred Dreyfus por espionaje colaborativo con el ejército alemán. La condena que impuso el tribunal militar fue la degradación y la inmediata deportación a la Isla del Diablo, ${ }^{55}$ una Colonia penal, donde residió de 1895 a 1899. Actualmente se sabe que la falsificación de la carta que inculpó a Dreyfus fue hecha por el comandante Hubert Joseph Henry bajo el mando del coronel Jean-Conrad Sandherr y que el culpable había sido el mayor Ferdinand Walsin Esterházy.

\footnotetext{
54 Resulta indispensable matizar el concepto de público a partir de sus prácticas productivas y de consumo, ya que el público ha tenido diferentes significados históricamente. Aunque el «público», como entidad social marcada por sus hábitos de consumo y crítica de arte y literatura, se originó en el siglo XVII, permaneció en las barreras infranqueables de la Corte: sólo la aristocracia urbana — que ocupaba un lugar en los asientos de los palcos: lecteurs, spectateurs, auditeurs - eran llamados le public. La asociación entre el público y la clase pensante respondía a una necesidad por totalizar socialmente las actividades políticas y artísticas de la aristocracia como público y, de aquel modo, instaurar el statu quo de la intelectualidad de una élite. Jürgen Habermas, Historia y crítica de la opinión pública. La transformación estructural de la vida pública. (Barcelona: Gustavo Gili, 1981), 69.

55 La Île du Diable se localiza a 11 kilómetros de la costa de la Guayana Francesa. Fue el asentamiento penal de Francia establecido desde 1851 por Napoleón III. La Isla del Diablo ha sido retratada por la literatura en obras como Papillon de Henri Charrière, La guillotina seca de René Belbenoit y por medio del personaje Florent en Le Ventre de Paris de Émile Zola.
} 
Los intentos de los familiares de Dreyfus por probar su inocencia terminaron convenciendo al presidente del Senado, Augusto ScheurerKestner, y al médico y diputado Georges Clemenceau. La lucha, además, consiguió una segunda audiencia ante el Ministerio de Guerra donde Esterházy fue absuelto y aclamado por los sectores nacionalistas del país. Las ovaciones recibidas develan que las pruebas que inculparon al general fueron maquinadas por los miembros del Consejo y apoyadas por un pueblo mayoritariamente antisemita. ${ }^{56} \mathrm{El}$ éxito de postulados raciales en contra de los judíos y de la mezcla de razas como los de Alphonse Toussenel, Edouard Drumont o Joseph Arthur Gabineau; asimismo las publicaciones de periódicos antisemitas como Diable à quatre, L'Univers, La Libre Parole, L'Intransigeant, La Lanterne, Le Petit Parisien, Le Petit Journal, Psst, Revue des Deux Mondes, L'Action Française, La Croix, entre otros, divulgaron postulados raciales que dividieron a la población con sentimientos xenófobos entre los que apoyaban las prácticas antisemitas y quienes las rechazaban. Las pruebas que condenaron por segunda vez al general Dreyfus ${ }^{57}$ en 1898, fueron suficientes para que el escritor Émile Zola tomara partido por la defensa y publicara, ese mismo año, el manifiesto que presionaría al Tribunal Supremo a una nueva apertura del caso: J'accuse...!

Voilà donc, monsieur le Président, les faits qui expliquent comment une erreur judiciaire a pu être commise ; et les preuves morales, la situation de fortune de Dreyfus, l'absence de motifs, son continuel cri d'innocence, achèvent de le montrer comme une victime des extraordinaires imaginations du commandant du Paty de Clam, du milieu clérical où il se trouvait, de la chasse aux « sales juifs », qui déshonore notre époque. ${ }^{58}$

El J'accuse...! es el manifiesto que, al denunciar los asuntos de Estado como problemáticas sociales xenófobas, demuestra que el escritor tiene poder para opinar y evidenciar las decisiones de gobierno que antes sólo pertenecían a un grupo minoritario. La opinión de Zola en la prensa francesa inaugura el surgimiento del intelectual público.

56 Para analizar el antisemitismo francés durante el siglo xIx, Cfr. Kalman, Rethinking Antisemitism; Diana R. Hallman, Opera, Liberalism, and Antisemitism.

57 María de Gracia Caballos Bejano ha estudiado y descrito el desarrollo de la prensa francesa y los postulados raciales en la Francia decimonónica durante el caso del general Dreyfus. Cfr. Caballos Bejano, "El ‘affaire’ Dreyfus". Además, Christophe Charle ha estudiado la prensa francesa como objeto de historia cultural, social y política en la Francia decimonónica y principios del siglo xx. Cfr. Christophe Charle, Le Siècle de la Presse 1830-1939 (París: Éditions du Seuil, 2004).

58 Artículo publicado por Émile Zola, titulado J'Accuse...! en L'Aurore (París), 13 de enero, 1898. Biblioteca Nacional de París, https://gallica.bnf.fr/ark:/12148/bpt6k701453s.texteImage. 
Aunque la opinión de Zola en el J'accuse...! se considera la culminación de su apoyo $^{59}$ a Dreyfus y pudiera ser ponderada como la mayor crítica pública en el siglo Xix francés a los asuntos de Estado, el autor difundió trabajos anteriores que notaban que los intereses de los intelectuales ya no eran los de la simple escritura de novelas de folletín. La campaña de Zola en apoyo al caso Dreyfus inició con la publicación de tres artículos en Le Figaro: «M. Scheurer-Kestner», «Le Syndicat» y «Procès-verbal». ${ }^{60}$ Tras la impresión de los tres artículos, el periódico Le Figaro mostró resistencia a emprender una oposición contra la milicia francesa por las publicaciones sufridas en contra del periódico y la presión de sus lectores. En apoyo al general Dreyfus, Zola fue obligado a abandonar sus proclamaciones en Le Figaro y a continuar su campaña con folletos ${ }^{61}$ en la editorial Fasquelle. El biógrafo Alexandre Zévaès comenta al respecto lo siguiente:

La publicación del último encuentra cierta resistencia de parte de la administración del periódico, y Zola cree prudente despedirse del público, comprendiendo la imposibilidad de continuar una campaña que disgusta a los lectores habituales del diario; él sabe muy bien que éste debe tener en cuenta los hábitos, los perjuicios y las prevenciones de su clientela. ${ }^{62}$

La retirada de Zola del periódico evidencia el gran acontecimiento del siglo: el escritor es consciente de la existencia de un público lector que comparte hábitos, prejuicios e intereses y, por ello, acepta su salida del mercado. El escritor de novelas de folletín en la segunda mitad del siglo XIX se enfrenta

59 El biógrafo de Zola, Alexandre Zévaès, escribió que, en un primer momento, al escuchar sobre la degradación pública del general, el novelista creyó, como todos los demás, en la culpabilidad de Dreyfus; sin embargo, el espectáculo y el entusiasmo del narrador le pareció de mal gusto. Dos años después, Bernard Lazare visitará a Zola para defender la causa de Alfred Dreyfus y las conversaciones con Marcel Prevost y con Louis Lebois fijarán su apoyo. Cfr. Zévaès, Zola, 192.

60 «M. Scheurer-Kestnen», del 25 de noviembre, fue el segundo artículo publicado en Le Figaro. El primero (16 de mayo) arremetía contra el antisemitismo existente en la sociedad francesa y se tituló «Pour les Juifs». A la publicación del 25 de noviembre, le siguió «Le Syndicat (primero de diciembre) con el objetivo de atacar la idea de la existencia de un sindicato judío en contra de los cristianos. El último ( 5 de diciembre) se tituló «Procès-verbal». Cfr. Zévaès, Zola, 193; Brown, Zola a Life, 726-728; Caballos Bejano, "El 'affaire' Dreyfus", 37-71.

61 La dificultad por encontrar un periódico que aceptara artículos en favor del general Alfred Dreyfus condujo a Émile Zola a publicar folletos en la editorial Fasquelle. El primero, del 14 de diciembre de 1897, se tituló «Lettre à la jeunesse». El segundo, del 6 de enero de 1898, «Lettre à la France». Por último, el tercer folleto, del 13 de enero de 1898, salió en el diario L'Aurore, y se tituló «J'Accuse...! Lettre au Président de la République». Ese mismo año, Le Figaro vuelve a publicar el 25 de noviembre un artículo de Zola titulado «La vérité est en marche, et rien ne l'arrêtera» y el 5 de junio de 1899, «Justice». La obra crítica y periodística de Zola está archivada bajo el nombre de «nouvelle champagne» en los periódicos sobre el caso Dreyfus. La cronología de los artículos de Zola ha sido publicada en la investigación de María de Gracia Caballos Bejano, "El ‘affaire’ Dreyfus"”.

62 Zévaès, Zola, 193. 
a un público dividido entre aquellos que reproducen el prejuicio antisemita como parte del saber de la época, y entre los que estuvieron cada vez más interesados en cuestionar la información de la autoridad por medio de la opinión pública. ${ }^{63}$

A partir de aquel momento, la campaña dreyfusiana no fue únicamente contra la milicia francesa, sino contra el antisemitismo existente en la mayoría de la sociedad, incluso entre los grupos de intelectuales. María de Gracia Caballos Bejano refiere que, durante el siglo XIx, los términos «dreyfusistas», «antidreyfus», «antidreyfusistas» son testimonio de los sentimientos xenófobos existentes en Francia: ${ }^{64}$ un apellido transformado en palabra con connotaciones negativas. Sin embargo, la polémica del significado de la palabra intellectuel es la muestra más sutil del antisemitismo francés, pues tras desprenderse de las connotaciones aristocráticas que la constriñeron, entrañó una pugna entre dos formas de hacer política: los intelectuales de la Tercera República y los que estaban en disputa con el régimen republicano. ${ }^{65}$ Aunque el grupo anti-republicano obtuvo numerosas ganancias con las publicaciones de folletines, no habrá de olvidarse que el intelectual estuvo en relación con una red de vínculos sociales producida por el capitalismo decimonónico que no pudo desatender, pero que sirvieron de herramientas para la difusión de ideas revolucionarias y críticas de su sociedad. ${ }^{66}$ No obstante, hubo escritores que no compartieron la idea de la intelectualidad y se nombraron a sí mismos

63 Para un estudio pormenorizado de la aparición de los nuevos públicos en correlación con la opinión pública Cfr. Habermas, Historia y crítica de la opinión pública.

64 Caballos Bejano, "El 'affaire 'Dreyfus", 39. Además, es posible consultar las diversas publicaciones en torno al caso Dreyfus y en contra del general Alfred Dreyfus: la sátira de Dreyfus vestido como un Judas que traiciona a su patria. Cfr. Dibujo de Dreyfus como Judas en Le Grelot (París), 11 de noviembre, 1894. Biblioteca Nacional de Francia, https://gallica.bnf.fr/ark:/12148/bpt6k125092w/f183.image. El artículo publicado en La Libre Parole el 6 de noviembre sobre la traición de Dreyfus. Cfr. "La trahison du juif Dreyfus", en La Libre Parole (París), 6 noviembre de 1894. Biblioteca Nacional de París, https://www.retronews.fr/journal/la-libre-parole/06novembre-1894/691/1953807/1. Cfr. Anuncio titulado Physiologie du flâneur en La Presse (París), 18 de mayo, 1841. Biblioteca Nacional de París, https://gallica.bnf.fr/ark:/12148/bpt6k62352r.texteImage.

65 Le Hir, "Stendhal ", 22.

66 Un ejemplo de ello fue Stendhal, para quien la verdadera labor del intelectual fue desafiar la hegemonía económica y llamar al orden al Estado para oponerse al poder de la clase pensante: la toma del poder del escritor. Cfr. Le Hir, "Stendhal", 32 y 33. Para ello, fue necesario que la literatura adquiriese una ética social, aun cuando estaba sujeta a condiciones materiales como los sueldos estables de los miembros de la Académie Française o las ventas masivas de las novelas en serie. Para Stendhal, el intelectual poseía una ética social cuando se atrevía a defender el interés general sin importar las condiciones económicas; sin duda, movido por la despreocupación de no recibir sueldo alguno de las publicaciones periódicas, estableció la autonomía como práctica crítica-literaria. El intelectual liberado, autónomo, pertenecía a «la clase del pensamiento» que se diferenció de otros grupos sociales. Las pautas libertarias debían evidenciarse en la estética novelística; no obstante, otros escritores, que para Stendhal no fueron considerados como partidarios de la «clase de pensamiento», también se opusieron al poder de los aristócratas; para éstos, las publicaciones en masa fueron el medio para promulgar sus ideas sociales. 
como «anti-intelectuales». La anti-intelectualidad, para Anatole France, ${ }^{67}$ significó respetar la inteligencia del otro y no meterse en asuntos ajenos. Es decir que, Anatole observó, específicamente en el caso Dreyfus, la gran falla del escritor: creer que su inteligencia podía sobrepasar la inteligencia del Estado. La lección, concluyó Anatole, fue dejar al Estado lo que pertenece al Estado. Por el contrario, la intelectualidad para Émile Zola significó el triunfo de la participación ciudadana en asuntos públicos, aunque esto lo llevara a la muerte.

Émile Zola murió asfixiado la noche del 28 de septiembre de 1902. Las noticias de la terrible muerte — suicidio, asesinato, accidente- se divulgaron por las calles de París. Tras numerosos embates entre los amigos del escritor y las autoridades, se fijó una fecha para el funeral: domingo 5 de octubre. En los jardines silenciosos de Montmartre se pronunciaron tres discursos: el del Ministro de Instrucción Pública y Bellas Artes, Joseph Chaumié; el del escritor y miembro de la Academia Francesa, Abel Hermant, y el del gran detractor de Zola, Anatole France. Finalizados los discursos, un grupo de hombres y mujeres salieron de los arrabales y las comunas obreras con una flor en la mano que dejaron caer sobre el cuerpo de Zola para gritar «Germinal! ¡Germinal!». ${ }^{68} \mathrm{El}$ mundo subrepticio parisino había encontrado en la novela de Germinal ${ }^{69}$ el llamado del movimiento obrero. Antes que los restos del escritor se removieran de Montmartre para asentarse en el Panteón de París, su obra había conseguido posicionarse entre los clásicos franceses más aclamados y aborrecidos por la crítica. Defensor del pueblo y de la verdad, Zola será recordado por las publicaciones de artículos y cartas en el contexto del conflicto social ocasionado por la polémica del caso Dreyfus.

Zola se convirtió en un intelectual público, ya que medió entre el lector y los asuntos de Estado, otorgó voz a los sujetos subalternos y luchó por la

\footnotetext{
67 Anatole France (1844-1924), reconocido escritor francés, formó parte de la Academia Francesa en 1896, destacó en géneros literarios como la lírica, la narrativa, el teatro y el ensayo. En los años del caso Dreyfus, Anatole criticó duramente a Émile Zola y se posicionó en contra del término «intelectual», aunque en favor del capitán Dreyfus. No obstante, al morir Zola en 1902, homenajeó la memoria del escritor con un discurso en su funeral.

68 He tomado las escenas sobre los discursos fúnebres de 1902 de dos biógrafos: Zévaès y Brown. Zévaès, Zola, 256; Brown, Zola a Life, 796.

69 En la literatura que antecedió a la novela Germinal, los proletarios se representaron por primera vez como medios para obtener la riqueza, aunque no aún como problema social ni como sujeto político: Maurice Talmeyr con la novela Le Grisou (1880), Yves Guyot con La famille Pichot: scènes de l'enfer social (1882) y Jules Verne con Les Indes noires (1877). Las novelas anteriores a Germinal describieron la vida minera con detalles científicos sin denunciar las condiciones deplorables en la que estaban suscritos los trabajadores; por tal motivo, la novela zoliana, al ser la primera en representar las verdaderas condiciones en las que vivían los obreros en París, se convirtió en un ícono del pueblo.
} 
participación ciudadana en asuntos político-militares. Un caso anómalo que se convertiría, posteriormente, en una parte sustantiva de la opinión pública.

\section{Conclusión}

En suma, el artículo justifica cómo la novela de folletín posibilitó la aparición del intelectual en el ámbito público. Más que un anacronismo, redefinir el papel del intelectual y sus implicaciones en la literatura francesa permite pensar la conexión entre el campo literario y el campo social; ya que los novelistas de folletín se convirtieron, con el paso del tiempo, en los portavoces del pueblo francés. El problema de la intelectualidad francesa es la puesta en escena de la relación entre escritura y opinión pública, entre los grupos letrados y el pueblo. Por consiguiente, esta investigación contextualiza la aparición del término intelectual para pensar la relación indiscernible entre prensa y opinión pública. Los resultados obtenidos muestran que la aparición de la intelectualidad en el siglo XIX estuvo marcada por dos sucesos en la literatura francesa: la aparición de los novelistas de folletín (en la primera mitad) y la crítica política encabezada por el novelista Émile Zola (en la segunda mitad).

En el primer suceso, algunos escritores de novelas de folletín no fueron considerados en su tiempo como intelectuales: Honoré de Balzac, Frédéric Soulié, Alexandre Dumas, entre otros, no solamente porque el término no estaba incorporado en el lenguaje de la época sino porque, en el caso de Eugène Sue, su influencia popular culminó en puestos pertenecientes al Estado. ${ }^{70}$ Las intervenciones públicas de estos novelistas podrían ser interpretadas como gestos propios de un intelectual público, ya que la mayoría de estas aproximaciones cumplían el objetivo específico de ser portavoces del pueblo. Desde esta perspectiva de análisis, la investigación puede continuarse con otras figuras literarias que participaron en la difusión de ideas de impacto público y del desplazamiento del antiguo régimen letrado a una estructura más democrática. Por lo tanto, los novelistas de folletín, al retratar las miserias de las clases subalternas y convertirse en portavoces del pueblo, pueden interpretarse como intelectuales en la medida que representaron los intereses del poder popular. 
Igualmente, el segundo suceso estuvo marcado por la oposición suscitada entre los defensores del general Alfred Dreyfus (los intelectuales) y los antiintelectuales (quienes respetaban la política estatal). El trabajo político del grupo de los intelectuales, organizado por el novelista Émile Zola, cuestionó las decisiones militares del Estado francés e inició una campaña en contra de las decisiones autoritarias del gobierno. Con la retirada del periódico Le Figaro, Zola evidenció la conciencia del escritor ante un público lector que no necesariamente requería de la mediación de los escritores en asuntos de la época. Los novelistas no debían encargarse solamente de las representaciones sociales, sino de los problemas políticos en las cuales el pueblo no tenía injerencia. Zola encarnó ideas morales del escritor, una conciencia del deber basada en un ideal político que creyó en la existencia de un orden más igualitario y justo.

\section{Bibliografía}

Armiño, Mauro. "Introducción”. En Crimenes a la francesa. Antología, 1-15. Madrid: Siruela, 2018.

Barel-Moisan, Claire. "Du Magasin à La Science illustrée. Hybridation du roman vernien dans l'écosystème de la revue". En Jules Verne et la culture médiatique. De la presse du XIXe siècle au steampunk. Editado por François-Emmanuël Boucher y Maxime Prevost, 37-54. Québec: Presse de L’Université Laval, 2019.

Barrès, Maurice. Scènes et doctrines du nationalisme. París: Félix Juven Éditeur, 1902.

Benoist, Jocelyn, Éléments de philosophie réaliste. París: Librairie Philosophique, 2011.

Birch, Edmund. Fictions of the press in nineteenth-century France. Cambridge: Palgrave studies in modern European literature, 2018.

Brown, Frederick. Zola a Life. Baltimore and London: Johns Hopkins University Press, 1996.

Burette, T.H. [Carta de junio 16 de T.H. Burette a Eugène Sue] En Eugène Sue, Mystères de Paris. París: Libraire de Charles Gosselin, 1843. 
Caballos Bejano, María de Gracia. "El 'affaire`Dreyfus: un caso de xenofobia y antisemitismo en los albores del siglo xIx. Implicaciones políticas y literarias en la prensa francesa". Philologia hispalensis 16, $\mathrm{n}^{\circ} 1$ (2002): 37 71. https://doi.org/10.12795/PH.2002.v16.i01.03.

Caricatura de Dreyfus. Le Grelot (París), 11 de noviembre, 1894. Biblioteca Nacional de Francia, https://gallica.bnf.fr/ark:/12148/bpt6k125092w/ f183.image.

Carles, Patricia y Desgranges, Béatrice, en Émile Zola, La Commune 1871 París: Chronos, 2018.

Castoriadis, Cornelius. "El imaginario social instituyente". Zona Erógena, $\mathrm{n}^{\circ}$ 35 (1977): 1-9. http://dx.doi.org/10.4067/S0718-65682011000100005.

Castoriadis, Cornelius. La Institución imaginaria de la sociedad. Traducido por Antoni Vicens. México: Tusquets, 2013.

Charle, Christophe. Le Siècle de la Presse 1830-1939. París: Éditions du Seuil, 2004.

Charle, Christophe. Los intelectuales en el siglo XIX. Precursores del pensamiento moderno. Traducido por Carlos Martín Ramírez. Madrid: Siglo Xxi, 2000.

Chartier, Roger. Cultura escrita, literatura e historia. Traducido por Alberto Cue. Ciudad de México: Fondo de Cultura Económica, 2006.

De Certeau, Michel. Una política de la lengua. Traducido por Marcela Carolina. Ciudad de México: Universidad Iberoamericana, 2008.

"Feuilleton du Petit Journal", Petit Journal (París), 31 de enero, 1863. https:/ / gallica.bnf.fr/ark:/12148/bpt6k588113x?rk=21459;2.

Feuilleton Les mystères de Paris en el periódico Journal des Débats. (París), 19 de junio, 1842. Biblioteca Nacional de París, https://gallica.bnf.fr/ ark:/12148/bpt6k4458735/f1.image.

Feuilleton titulado Hervé. (París), 13 de diciembre, 1842. Biblioteca Nacional de París, https://gallica.bnf.fr/ark:/12148/bpt6k429063z/f1.image.

Flaubert, Gustave, Razones y osadías. Traducido por Jordi Llovet. Buenos Aires: Edaf, 1997.

Habermas, Jürgen. Historia y crítica de la opinión pública. La transformación estructural de la vida pública. Traducido por Antonio Domenech. Barcelona : Gustavo Gili, 1981. 
Hallman R., Diana. Opera, Liberalism, and Antisemitism in Nineteenth-Century France. Cambridge: Cambridge University Press, 2002.

Jaurès, Jean. "La trahison du juif Dreyfus". La libre Parole (París), 6 noviembre de 1894. Biblioteca Nacional de París, https://www.retronews.fr/ journal/la-libre-parole/06-novembre-1894/691/1953807/1

Jennings, Jeremy. Intellectuals in twentieth-century France. Nueva York: Palgrave Macmillan, 1993.

Kalifa, Dominique. Los bajos fondos. Historia de un imaginario. Ciudad de México: Instituto Mora, 2018.

Kalman, Julie. Retbinking Antisemitism in Nineteenth-century France. Cambridge: Cambridge University Press, 2010.

Le Constitutionnel, Journal du commerce, politique et littéraire (París), 23 de marzo, 1844. https://gallica.bnf.fr/ark:/12148/bpt6k666675g/f1.image.

Le Hir, Marie-Pierre. "Stendhal etl'invention de l'intellectuel". Nineteenth-Century French Studies, no 1 y 2 (2007): 21-44. https://doi.org/10.1353/ ncf.2007.0080.

Lyons, Martyn. Readers and society in nineteenth-century France. Nueva York: Palgrave, 2001.

Molina, Hebe Beatriz. Cómo crecen los hongos: la novela argentina entre 1838 y 1872. Buenos Aires: Teseo, 2011.

O’Neil-Henry, Anne. Mastering the Marketplace. Popular literature in nineteenth-century France. Nebraska: University of Nebraska Press, 2017.

Ory, Pascal y Jean-François Sirinelli. Les intellectuels en France de l'affaire Dreyfus à nos jours. París: Armand Colin, 1986.

Ory, Pascal, director. Dernières questions aux intellectuels. París: Olivier Orban, 1990.

"Physiologie du flâneur", La Presse (París), 18 de mayo, 1841. https://gallica. bnf.fr/ark:/12148/bpt6k62352r.texteImage.

Pike, David L. Metropolis on the Styx. The Underworlds of Modern Urban Culture, 1800-2011. Nueva York: Cornell University Press, 2007.

Sand, Shlomo. ¿El fin del intelectual francés?: De Zola a Houellebecq. Traducido por Alcira Bixio. Madrid: Ediciones Akal, 2017. 
Suárez de la Torre, Laura. "Estudio introductorio". En Tras las buellas de Eugenio Sue. Lectura, circulación y apropiación de Los misterios de París. Coordinado por Laura Suárez de la Torre, 1- 47. Ciudad de México: Historia/ Instituto Mora/Conacyt, 2015.

Sue, Eugène. Mystères de Paris. París: Libraire de Charles Gosselin, 1843.

Thérenty, Marie-Eve. "Los misterios urbanos en el siglo XIx: un primer episodio de la mundialización mediática". En Tras las huellas de Eugenio Sue. Lectura, circulación y apropiación de Los misterios de París. Coordinado por Laura Suárez de la Torre, 27-54. Ciudad de México: Historia/Instituto Mora/Conacyt, 2015.

Warner, Michael. Públicos y contrapúblicos. Barcelona: Universidad Autónoma de Barcelona, 2018.

Zermeño, Guillermo. Historias conceptuales. Ciudad de México: El Colegio de México, 2017.

Zévaès, Alexandre. Zola. Trad. Luis Enrique Délano. Ciudad de México: Biografías Gandesa, 1958.

Zola, Émile. “J'Accuse...!”. L’Aurore (París), 13 de enero, 1898. https:// gallica.bnf.fr/ark:/12148/bpt6k701453s.texteImage.

Zola, Émile. Yo acuso. La verdad en marcha. Trad. José Elías. Madrid: Tusquets, 2004. 